\title{
Uso de conchas de marisco na fabricação de blocos vazados de concreto simples para alvenaria
}

Uma das atividades de relevância desenvolvidas no município de Igarassu-PE, corresponde à pesca de marisco Anomalocardia brasiliana, com a qual a comunidade pesqueira local mantém uma expressiva relação de dependência social, cultural e econômica. O processo de beneficiamento do marisco Anomalocardia brasiliana, após a extração do molusco, gera resíduo de conchas, cujo descarte, em volume considerável em ambiente de mangue, provoca assoreamento de grandes áreas e, consequente, desequilíbrio ambiental, refletido, principalmente, pela redução da cadeia alimentar, além de provocar o desencadeamento da proliferação de vetores e condições de riscos de acidentes. A pesquisa objetivou a verificação da viabilidade de uso do mencionado resíduo, localizado na comunidade Beira Mar II, município de Igarassu-PE, na produção de blocos vazados de concreto simples para alvenaria, a partir da formulação de distintas composições de traços, visando à determinação da composição ótima. Foi realizada, portanto, a substituição de percentuais de massa da brita usada do traço convencional do concreto, por equivalente massa de conchas de marisco Anomalocardia brasiliana moídas em moinho de discos com espaçamento entre discos correspondente a $9,5 \mathrm{~mm}$. Esses blocos produzidos com as conchas de marisco Anomalocardia brasiliana, nas condições granulométricas impostas pela moagem e formulações de traços préestabelecidos, foram utilizados como corpos-de-prova para submissão a testes de verificação de qualidade. A produção dos blocos foi realizada de acordo com as recomendações das normas ABNT- NBR 6136:2016 - Blocos vazados de concreto simples para alvenaria - requisitos; e os ensaios absorção de água, determinação da área líquida, resistência à compressão e retração por secagem, realizados de acordo com a norma ABNT- NBR 12118:2013 - Blocos vazados de concreto simples para alvenaria - métodos de ensaio. Os resultados dos ensaios indicaram que os blocos produzidos com conchas de marisco Anomalocardia brasiliana, em todas as condições de traço, podem ser usados em alvenaria com função estrutural, sendo categorizados na classe B. A melhor condição de substituição, representada por $100 \%$ de permuta brita/concha, atendeu os requisitos normativos de resistência. $O$ uso das conchas incorrerá na agregação de vantagens econômicas e sociais, pela contribuição na ampliação de postos de trabalho e renda e da redução dos impactos ambientais causados pelo descarte inadequado do resíduo resultante do beneficiamento da pesca artesanal de mariscos Anomalocardia brasiliana.

\section{Use of shell fishing in the manufacture blocks cast of simple concrete for masonry}

\begin{abstract}
One of the relevance activities in the city of Igarassu-PE corresponds to shell fishing Anomalocardia brasiliana, in which the local fishing community maintains an expressive social relation, cultural and economic dependence. The shell fishing Anomalocardia brasiliana processing, after the extraction of the mollusc, generates shells residue, which discard, in considerable volume in a mangrove, can cause silting in large areas and, therefore, environmental imbalance, mainly reflected by the reduction of the food chain, in addition to the triggering of vectors and accident risk. The aim of this research is to verify the feasibility of using this residue, located in Beira Mar II community, city of Igarassu-PE, to product a simple concrete masonry blocks, from the formulation of different trace compositions, aiming at the determination of the optimal composition. Therefore, the percentage of mass used on crushed stone of the conventional concrete traces was replaced by the equivalent mass of shell fishing Anomalocardia brasiliana ground in a disc mill with spacing between disks corresponding to $9.5 \mathrm{~mm}$. These blocks produced with shell fishing Anomalocardia brasiliana in the granulometric conditions imposed by the milling and formulations of pre-established traits were used as test pieces for submission to quality verification tests. The production of the blocks was carried out according to the recommendations of ABNT-NBR 6136:2016's standards - blocks cast of simple concrete for masonry - requirements and water absorption, liquid area determination, compressive strength and drying shrinkage tests were performed in accordance with ABNT-NBR 12118:2013 - concrete blocks for masonry - test methods. The tests results indicated that the blocks produced with shell fishing Anomalocardia brasiliana, under all trace conditions, can be used in masonry with structural function, being categorized in class B. The best substitution is represented to change $100 \%$ gravel/shell, followed the normative resistance requirements. The use of shells would result in the aggregation of economic and social advantages, by the development of jobs and the reduction of environmental impacts caused by the inadequate disposal of the waste resulting from the processing of artisanal shell fishing Anomalocardia brasiliana.
\end{abstract}

Keywords: Shellfish; Shell; Precast; Artisanal fishing; Environment.

Topic: Desenvolvimento, Sustentabilidade e Meio Ambiente

Reviewed anonymously in the process of blind peer.
Received: 10/06/2018 Approved: 24/07/2018
Referencing this:

CALDAS, A. A.. Uso de conchas de marisco na fabricação de blocos vazados de concreto simples para alvenaria. Revista Ibero Americana de Ciências Ambientais, v.9, n.5, p.248-257, 2018. DOI: http://doi.org/10.6008/CBPC2179-6858.2018.005.0022 


\section{INTRODUÇÃO}

O destino do rejeito de conchas de marisco Anomalocardia brasiliana vem preocupando autoridades e vigilância sanitária, pois muitos produtores o lançam no mar, em áreas de mangue ou em terrenos baldios. Os efeitos socioambientais danosos da disposição incorreta das conchas de marisco Anomalocardia brasiliana já vêm sendo sentidos, principalmente, pela população próxima aos locais onde é desenvolvida essa atividade pesqueira.

A grande quantidade de conchas resultante do descarte da atividade pesqueira artesanal do marisco Anomalocardia brasiliana no município de Igarassu/PE, realizado pelos marisqueiros da comunidade Beira Mar II, está causando relevantes problemas ambientais devido à ocupação de áreas territoriais privadas e públicas e, em especial, de áreas de mangue e de trechos das margens do rio Igarassu, configurando-se como de gravidade, devido às suas distribuições geográficas aleatórias e dos seus expressivos volumes.

Atualmente, a reciclagem de materiais constitui um dos mais importantes temas para estudo, uma vez que envolve aspectos técnicos, econômicos e ambientais. A reciclagem é bastante utilizada em países do primeiro mundo, onde as matérias primas têm aspectos estratégicos. A construção civil é o setor da atividade tecnológica que consome grande volume de recursos naturais e parece ser o mais indicado para absorver os resíduos sólidos.

Por outro lado, a produção de brita destinada à construção civil vem, paulatinamente, promovendo degradação ambiental pelas inevitáveis consequências promovidas pelos desmontes de maciços rochosos. A proximidade de pedreiras de centros habitados é uma decorrência natural da forte influência do custo dos transportes no preço final do produto. Isso ocorre, principalmente, com os agregados, devido ao seu baixo valor unitário. Os fatores geológicos ligados à localização natural da jazida e ao grande volume das reservas, proporcionando longa vida útil aos empreendimentos, são fatores rígidos e imutáveis que impedem a mudança das áreas de extração (BACCl et al., 2006).

Os efeitos ambientais estão associados, de modo geral, às diversas fases de exploração dos bens minerais, e, em particular das rochas para uso como brita, à abertura da cava, (retirada da vegetação, escavações, movimentação de terra e modificação da paisagem local), ao uso de explosivos no desmonte de rocha (sobre pressão atmosférica, vibração do terreno, ultra lançamento de fragmentos, fumos, gases, poeira, ruído), ao transporte e beneficiamento do minério (geração de poeira e ruído), afetando os meios como água, solo e ar, além da população local (BACCl et al., 2006).

Em sendo assim, a utilização industrial de conchas acumuladas em rejeitos resultantes da atividade marisqueira de Igarassu-PE, poderá se constituir, decisivamente, numa forma de minimizar impactos ambientais, resultante de relevância não desprezível para a minimização de impactos da mineração de rochas para fins de produção de brita. 


\section{REVISÃO TEÓRICA}

O marisco Anomalocardia brasiliana é um animal de corpo mole e coberto por uma concha protetora. Seu habitat natural são os lagos, mares e oceanos. Se alimenta de plâncton, constituído de vegetais e animais aquáticos. O esqueleto é externo, isto é, exoesqueleto, resistente em forma de concha para sua proteção (BOICKO, 2004).

\section{Constituição físico-química da concha de marisco anomalocardia brasiliana}

De acordo com Silva et al. (2010), nácar é uma substância dura e brilhante composta de camadas de conchiolina, uma escleroproteína complexa formada de queratina, colágeno e elastina secretada pelo molusco e intercalada por camadas de calcita ou aragonita (cristais de carbonato de cálcio - $\mathrm{CaCO}$ ), proporcionando alta dureza e rigidez à concha.

Bessler et al. (2008) citam que, tanto a aragonita, como a calcita e a vaterita, são formas cristalinas do que cristaliza no sistema ortorrómbico, sendo muito menos estável e mais solúvel em água que a calcita. Forma geralmente agregados fibrosos com gipsito e minerais de ferro. A aragonita é um mineral originário de sedimentos hidrotermais, constituído por cristais prismáticos de carbonato de cálcio.

\section{Alternativa de aproveitamento dos resíduos sólidos de marisco anomalocardia brasiliana remar (resíduos sólidos da mariscagem)}

Segundo Petrielli (2008), estudos feitos com pessoas idosas, no Japão, confirmam que o carbonato de cálcio extraído das conchas é mais bem absorvido com maior eficiência pelo intestino e aumenta a densidade mineral dos ossos, principalmente na região lombar em pessoas com deficiência em cálcio, hiperparatireoidismo secundário.

Para Oliveira (2016), as problemáticas socioambientais causadas pelo descarte inadequado dos Remar provocam pesquisadores ao desenvolvimento de estudos e modelos aplicados para diversos setores, tais como: a) construção civil (YOON et al., 2003); b) combate a incêndios; c) agrícola (SANT'ANNA, 2007); d) aviário ou pecuário; e) farmacêutico (SANT'ANNA, 2007); f) tratamento de águas residuais; g) educação (OLIVEIRA, 2013a).

\section{Impactos ambientais associados ao beneficiamento de marisco anomalocardia brasiliana}

O Brasil é o segundo produtor aquícola da américa latina, com cerca de 270 mil toneladas por ano. 0 Brasil está bem abaixo do Chile que tem uma produção superior a 600 mil toneladas/ano. A produção aquícola brasileira começou a crescer rapidamente depois de 1995 com o aumento da carcinicultura (cultivo de camarão em cativeiro), apesar de a aquicultura comercial ter demonstrado um crescimento constante, sobretudo a partir do ano 2000 (DIEGUES, 2010).

Para Silva-Cavalcanti (2011), que realizou estudo na comunidade de Beira- Mar II, Município de Igarassu/PE, litoral norte de Pernambuco, estima-se que a quantidade de Remar despejada nas margens do Rio Igarassu (conhecido como Rio São Domingos), responsável pelo assoreamento de vários trechos do rio, 
bem como sua navegação. Para Diegues (2010), deve-se ressaltar que parte desse aumento pode ser creditado à melhoria das estatísticas coletadas pelo Instituto do Meio Ambiente e dos Recursos Naturais Renováveis (Ibama) e pelo Ministério da Pesca e Aquicultura (MPA).

Para Oliveira (2016), o termo 'resíduo' pode ser facilmente confundido com 'lixo', título geralmente empregado para qualquer resquício material oriundo das atividades antrópicas, que compõem-se basicamente de sobras de alimentos, papéis, plásticos, vidros, metais, couros, madeiras, gases, sabões e outras substâncias.

Tachizawa (2007), afirma que uma das preocupações da década de 90 foi a questão ambiental, tornando-se uma das principais questões até os dias de hoje. Nas últimas décadas, os insumos naturais vêm sendo extraídos do ambiente natural, e muitas vezes utilizados de forma inadequada, quer seja por indivíduos, por comunidades ou por setores privados, provocando uma escassez e desordem destes no meio ambiente.

\section{Bloco vazado de concreto simples no Brasil}

No Brasil, os blocos de concreto foram utilizados em 1940 na obra do conjunto habitacional do Realengo na Cidade do Rio de Janeiro. Foram importadas dos Estados Unidos nos meados de 1950, entrando para história esses equipamentos, as primeiras máquinas para fabricação de blocos em nosso país (BARBOSA, 2004).

Para Clementino (2014), o concreto é o material de construção resultante da mistura, em quantidades racionais, de aglomerante, agregados e água. De uma forma geral, o aglomerante mais usado é o cimento Portland, e os agregados são a areia (agregado miúdo) e a brita (agregado graúdo). Logo após a mistura, o concreto deve possuir plasticidade, o suficiente para as operações de manuseio, transporte e lançamento em fôrmas. Adquirindo assim, coesão e resistência com o passar do tempo, devido às reações que se processam entre aglomerante e água.

Buttler (2007), afirma que os concretos de consistência seca, empregados na produção de blocos, possuem características de um concreto levemente umedecido, sendo necessária a utilização de máquinas que conferem compacidade à mistura para retirada do ar aprisionado. Para Buttler (2007), os blocos de concreto devem cumprir os seguintes requisitos: a) coesão no estado fresco; b) máxima compacidade; c) resistência mecânica compatível; d) textura superficial. A composição ideal entre os agregados é um dos primeiros passos para a dosagem dos concretos secos. Esse procedimento se baseia na formulação de uma mistura com um mínimo de vazios possíveis, visando alcançar as maiores massas unitárias. A partir de então surgiram diversos esforços para a modernização da fabricação de blocos de concreto, assim como da sua utilização na alvenaria. Entretanto, os materiais utilizados, procedimentos de dosagem e o esquema do processo produtivo são ainda basicamente os mesmos (SALVADOR FILHO, 2007). 


\section{METODOLOGIA}

Oliveira (2016), cita que o conjunto arquitetônico e paisagístico de Igarassu foi inscrito no livro arqueológico, etnográfico e paisagístico do IPHAN, e é um dos principais testemunhos materiais do Brasil Colônia, através tanto de bens culturais edificados de pedra e cal, herança da colonização portuguesa, quanto de remanescentes, vegetação nativa ou introduzida nos primeiros anos da colonização.

As conchas de marisco Anomalocardia brasiliana, objeto do presente estudo, encontravam-se acumuladas em depósito existente na margem direita do rio Igarassu, num trecho do rio em que o seu curso fica circunscrito aos limites da comunidade Beira Mar II, no município de Igarassu/PE. As diferentes fases do estudo, requereram suporte de dispositivos específicos para as suas consecuções. As máquinas, equipamentos e elementos técnicos utilizados, encontram-se discriminados do Quadro 1.

Quadro 1: Máquinas, equipamentos e elementos técnicos utilizados e as suas aplicações.

\begin{tabular}{|c|c|}
\hline MATERIAL & APLICAÇÃO \\
\hline \multicolumn{2}{|c|}{ Moinho de discos marca Renard, modelo MDA 200 Promoção da comunicação das conchas de marisco } \\
\hline \begin{tabular}{|llll} 
Peneiras & ABNT NBR & no & $8(\# 2,36 \mathrm{~mm})$ \\
& & & \\
& &
\end{tabular} & $\begin{array}{l}\text { Adequar as partículas da amostra de conchas de marisco moída à granulometria } \\
\text { da brita utilizada na produção de blocos vazado de alvenaria simples, reduzindo; } \\
\text { o teor de material fino }(<\# 2,36 \mathrm{~mm})\end{array}$ \\
\hline $\begin{array}{l}\text { Balança digital, com } 3 \text { casas decimais, marca } \\
\text { Magna, modelo Tor Rey }\end{array}$ & $\begin{array}{l}\text { Orientação da definição das massas das alíquotas da amostra de concha e de } \\
\text { brita, utilizadas nos diferentes traços de concreto }\end{array}$ \\
\hline $\begin{array}{l}\text { Balança digital, com } 03 \text { casas decimais, marca } \\
\text { Marte, modelo TBA } 013\end{array}$ & Fazer conferência do peso dos blocos \\
\hline $\begin{array}{l}\text { Máquina de fabricação de blocos, marca Trillor, } \\
\text { modelo } 4200\end{array}$ & Confecção dos corpos de prova \\
\hline Estufa, para $(110+/-5)$ ㅇ, marca Quimis & Secagem dos blocos - absorção \\
\hline Estufa, para $(110+/-5)$ @C, marca Fanem & Secagem dos blocos - retração \\
\hline \multicolumn{2}{|l|}{$\begin{array}{l}\text { Máquina de ensaio de resistência, com capacidade } \\
\text { para } 200 \text { tf, marca PAVITEST, identificação TPH } 009\end{array}$} \\
\hline $\begin{array}{l}\text { Relógio comparador, com } \\
\text { sensibilidade de } 0,001 \mathrm{~mm} \text {, marca } \\
\text { Mitutoyo, modelo padrão }\end{array}$ & Medição da retração linear dos blocos. \\
\hline $\begin{array}{l}\text { Paquímetro analógico com resolução de } 0,05 \mathrm{~m} \\
\text { marca Mitutoyo }\end{array}$ & \\
\hline
\end{tabular}

\section{Amostragem}

As amostras de concha de marisco foram coletadas na comunidade Beira Mar II, Igarassu/PE. Foram coletados manualmente. As amostras foram retiradas da superfície seca de várias montanhas e transportadas para a lavagem. As amostras assim moídas, foram passadas na peneira ABNT no 8 (\# 2,36 mm), objetivando a redução dos finos de processo de moagem. A amostra utilizada nos estudos, compreendeu a parcela retida na peneira ABNT no 8 e após peneiramento.

Foram calculadas as massas de conchas de marisco substitutivas correspondentes aos percentuais de $0 \%, 10 \%, 15 \%, 50 \%, 75 \%$ e $100 \%$, que participaram, individualmente, dos seis diferentes traços de concreto utilizados na produção dos corpos de prova objeto de estudos. Após fabricação, os blocos foram colocados em estante e levados, posteriormente, para a estufa com temperatura ambiente, permanecendo por 24 horas. Depois da secagem, os blocos foram embalados em plástico bolha com objetivo de evitar danos físicos 


\section{RESULTADOS E DISCUSSÃO}

Nos itens a seguir, estão esboçadas as discussões que permitiram a compreensão do comportamento tecnológico dos blocos de concreto simples para alvenaria, utilizando conchas de marisco em substituição à brita convencional. As discussões foram fundamentadas nos resultados de ensaios normalizados, realizados durante o presente estudo, e em dados da literatura.

\section{Análise química por fluorescência de raios $\mathbf{x}$}

As conchas de marisco, revelaram mediante análise por fluorescência de raios $\mathrm{X}$, citada por Silva (2014), teor de $56,04 \%$ de $\mathrm{CaO}, 43,07 \%$ de $\mathrm{CO}_{2}$ e traços de outros óxidos. O óxido de cálcio pode ser um constituinte da estrutura cristalina, tanto do mineral calcita, quanto do mineral aragonita, para cuja distinção se faz necessária a análise mineralógica por difração de raios $X$.

\section{Análise qualitativa por difração de raios $\mathbf{x}$}

Os picos revelados pelo difratograma de raios $\mathrm{X}$ da concha de marisco, correspondem a um conjunto de espaçamentos interplanares, medidos em ângstrons, representativos, exclusivamente, da estrutura cristalina do mineral aragonita (Figura 1).

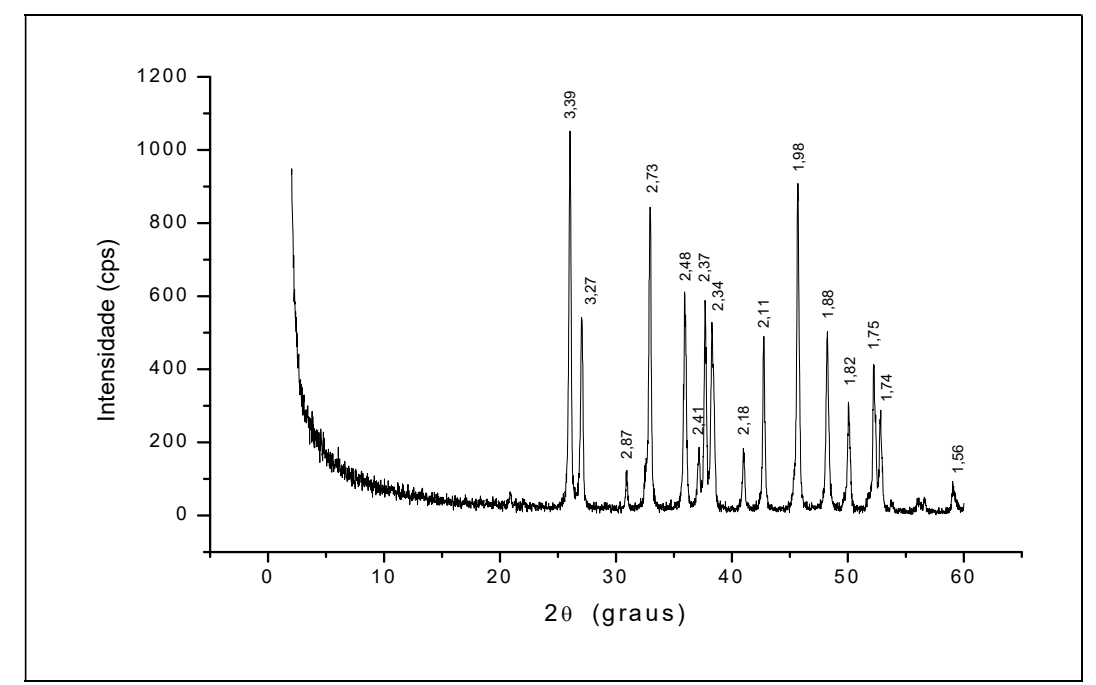

Figura 1: Difratograma de raios X da concha de marisco Anomalocardia Brasília.

Ensaios de absorção de água e blocos vazados de concreto nos percentuais de $0 \%, 10 \%, 15 \%, 50 \%, 75 \%$ e $100 \%$ de concha de marisco anomalocardia brasiliana

O volume de água mal dosado por ocasião do traço do concreto pode ocasionar o surgimento de vazios no bloco. As condições de absorção de água, pelo bloco, são indicativas, portanto, de condição de resistência implícita e de possibilidade de surgimento de condições ambientais adversas futuras, considerando, neste caso, a perspectiva da aplicação do bloco em obras da construção civil. Em sendo assim, a norma ABNT NBR 12118: 2013 - Blocos vazados de concretos simples para alvenaria - Métodos de Ensaio - Absorção de Água estabelece os limites de absorção de água para blocos em diferentes classes. 
Os valores apresentados dos resultados dos ensaios de absorção de água em blocos de concreto do presente estudo, atendem aos requisitos da referida norma, para bloco classe $A$, tanto no que diz respeito ao item valor individual, quanto ao item valor médio que são definidos como sendo, respectivamente, $\leq 9 \%$ e $\leq 8 \%$ (Tabela 1$)$

Tabela 1: Resultado do ensaio de absorção de água.

\begin{tabular}{|c|c|c|c|c|c|c|c|c|c|c|}
\hline \multirow{5}{*}{$\begin{array}{l}\text { VARIAÇÃO EM } \\
\text { MASSA DA CONCHA } \\
\text { (\%) }\end{array}$} & \multicolumn{10}{|c|}{ ABSORÇÃO DE ÁGUA (\%) } \\
\hline & \multicolumn{3}{|c|}{$\begin{array}{l}\text { CORPO DE PROVA } \\
\text { (№) }\end{array}$} & \multirow[t]{4}{*}{ MÉDIA } & \multirow{2}{*}{\multicolumn{6}{|c|}{$\begin{array}{l}\text { RECOMENDAÇÕES DA NORMA NBR ABNT 6136:2016 } \\
\text { CLASSE* }\end{array}$}} \\
\hline & \multirow{3}{*}{1} & \multirow{3}{*}{2} & \multirow{3}{*}{3} & & & & & & & \\
\hline & & & & & \multicolumn{4}{|c|}{\begin{tabular}{l|l} 
CLASSE $^{*}$ \\
A
\end{tabular}} & \multicolumn{2}{|l|}{$\mathbf{C}$} \\
\hline & & & & & INDIVIDUAL & MÉDIA & INDIVIDUAL & MÉDIA & INDIVIDUAL & MÉDIA \\
\hline 0 & 7,2 & 6,8 & 7,5 & 7,2 & \multirow{6}{*}{$\leq 9,0$} & \multirow{6}{*}{$\leq 8,0$} & \multirow{6}{*}{$\leq 10,0$} & \multirow{6}{*}{$\leq 9,0$} & \multirow{6}{*}{$\leq 11,0$} & \multirow{6}{*}{$\leq 10,0$} \\
\hline 10 & 6,8 & 6,7 & 6,1 & 6,5 & & & & & & \\
\hline 15 & 7,5 & 6,1 & 6,2 & 6,6 & & & & & & \\
\hline 50 & 5,8 & 6,8 & 6,1 & 6,2 & & & & & & \\
\hline 75 & 5,9 & 5,8 & 5,9 & 5,9 & & & & & & \\
\hline 100 & 5,7 & 5,6 & 5,6 & 5,6 & & & & & & \\
\hline
\end{tabular}

(*) Classes A e B: Com função estrutura; Classe C: Com ou sem função estrutural.

Ensaios de resistência à compressão em blocos vazados de concreto nos percentuais de $0 \%, 10 \%, 15 \%$, $50 \%, 75 \%$ e $100 \%$ de concha de marisco anomalocardia brasiliana

Segundo Buttler (2007), quanto mais água puder ser incorporada à mistura, para uma determinada quantidade de cimento, maior será a resistência e compacidade e maior será a plasticidade que facilitará a prensagem do material nas formas da máquina; frisa que se essa quantidade for grande ocorrerá problemas de desforma e deformações indesejáveis nas peças durante o transporte e a principal fonte de variabilidade no ato do proporcionamento é a variação da umidade dos agregados, afetando a compacidade da mistura e a resistência à compressão.

Tabela 2: Resultado do ensaio de resistência à compressão aos 28 dias.

\begin{tabular}{|c|c|c|c|c|c|c|c|c|c|c|}
\hline \multirow{4}{*}{$\begin{array}{l}\text { VARIAÇÃO EM MASSA DA } \\
\text { CONCHA } \\
\text { (\%) }\end{array}$} & \multicolumn{10}{|c|}{ RESISTÊNCIA À COMPRESSÃO (MPa) } \\
\hline & \multicolumn{6}{|c|}{ CORPO DE PROVA (№) } & \multirow{2}{*}{$\begin{array}{l}\text { MÉDIA } \\
\left(f_{b k}\right)\end{array}$} & \multicolumn{3}{|c|}{$\begin{array}{l}\text { RECOMENDAÇÕES DA NORMA NBR ABNT } \\
6136: 2016 \\
\text { CLASSE }\left(f_{\mathrm{bk}}\right)^{*}\end{array}$} \\
\hline & & & & & & & & & & \\
\hline & $\underline{1}$ & 2 & $\underline{3}$ & $\underline{4}$ & $\underline{5}$ & $\underline{6}$ & & $\underline{\mathbf{A}}$ & $\underline{B}$ & C \\
\hline 0 & $\overline{5}, 8$ & $\overline{5,9}$ & $\overline{7}, 3$ & $\overline{6}, 4$ & $\overline{6}, 0$ & $\overline{6}, 8$ & 5,7 & \multirow{6}{*}{$f_{b k} \geq 8,0$} & \multirow{6}{*}{$4,0 \leq f_{b k}<8,0$} & \multirow{6}{*}{$f_{b k} \geq 3,0$} \\
\hline 10 & 6,2 & 5,6 & 6,2 & 5,9 & 6,4 & 6,6 & 5,4 & & & \\
\hline 15 & 5,5 & 6,0 & 6,6 & 6,5 & 5,7 & 5,6 & 5,4 & & & \\
\hline 50 & 6,4 & 6,2 & 6,3 & 6,2 & 6,9 & 5,6 & 5,5 & & & \\
\hline 75 & 5,6 & 6,2 & 5,7 & 6,5 & 5,8 & 5,4 & 5,3 & & & \\
\hline 100 & 5,2 & 5,0 & 4,6 & 4,9 & 5,1 & 4,9 & 4,6 & & & \\
\hline
\end{tabular}

$\left({ }^{*}\right)$ Classes A e B: Com função estrutural; Classe C: Com ou sem função estrutural.

De acordo com a NBR 6136: 2016 - Blocos vazados de concreto simples para alvenaria - Requisitos e a NBR 12118: 2013 - Blocos vazados de concreto simples para alvenaria - Métodos de ensaio, os valores apresentados nos ensaios de resistência à compressão atendem ao requisito para um bloco de classe $B$ (Tabela 2). Os ensaios foram realizados aos 28 dias.

A resistência à compressão é uma condição essencial para os blocos estruturais, por sua função e durabilidade. Como já foi mencionado, a absorção de água e a impermeabilização da parede estão correlacionadas a esta propriedade, onde f fk é resistência característica à compressão do bloco. De acordo 
com a norma ABNT NBR 6136:2016 - Blocos vazados de concreto simples para alvenaria, os valores apresentados nos ensaios atendem aos requisitos para um bloco de classe $B\left(4,0 \leq f_{b k} \leq 8,0\right)$. 0 decréscimo da resistência do bloco em função do aumento da participação das conchas de marisco no traço de concreto, tem relação com a menor resistência da concha de marisco, em comparação com a da brita.

\section{Retração por secagem}

Segundo Senisse et al. (2010), o fenômeno da retração é definido como uma deformação de contração da matriz cimentícia, iniciada imediatamente após a mistura dos materiais secos com a água, isto é, a partir do início do processo de hidratação do cimento. A ocorrência do mesmo, nos materiais cimentícios, é considerada inevitável, uma vez que durante o processo de endurecimento do material, o calor gerado pelas reações de hidratação do cimento, conjuntamente com o seu processo de secagem e com as variações térmicas do ambiente externo, podem originar uma tendência de fissuração, que pode redundar em prejuízos para a resistência à compressão do concreto.

Tabela 3: Determinação das massas.

\begin{tabular}{|c|c|c|c|c|c|c|c|c|}
\hline \multirow{2}{*}{$\begin{array}{ll}\text { CORPO } & \text { DE } \\
\text { PROVA (No) } & \end{array}$} & MASSA (g) & & \multirow[b]{2}{*}{ DIAS DE } & \multirow{2}{*}{\multicolumn{2}{|c|}{$\begin{array}{lrll}\text { APÓS } & 7 & \text { DIAS } & \text { DE } \\
\text { SECAGEM } & & \end{array}$}} & \multirow{2}{*}{\multicolumn{3}{|c|}{$\begin{array}{lrlr}\text { APÓS } & 9 & \text { DIAS } & \text { DE } \\
\text { SECAGEM } & & \\
\end{array}$}} \\
\hline & $\begin{array}{l}\text { APÓS 48h } \\
\text { IMERSÃO }\end{array}$ & $\begin{array}{l}\text { APÓS } 5 \\
\text { SECAGEM }\end{array}$ & & & & & & \\
\hline 1 & 13624 & 12927 & & 12927 & & 12927 & & \\
\hline 2 & 13603 & 12906 & & 12905 & & 12905 & & \\
\hline 3 & 13387 & 12690 & & 12689 & & 12688 & & \\
\hline
\end{tabular}

A retração por perda de água ou retração por secagem pode ocorrer na pasta, argamassa ou concreto no estado fresco ou endurecido (BUTTLER, 2007). As Tabelas 3 e 4 apresentam, respectivamente, os resultados das determinações das massas e das retrações por secagem, de acordo com a NBR 6136:2016. Foram analisados 03 corpos de prova contendo, nas suas composições, 100\% de concha de marisco. De acordo com os requisitos da Norma NBR ABNT 6136:2016 a retração por secagem de bloco de concreto deve ser $\leq 0,065 \%$. 0 ensaio realizado permitiu verificar que a amostra está em conformidade com a especificação normativa pertinente.

Tabela 4: Determinação da retração por secagem.

\begin{tabular}{|l|l|l|l|l|l|}
\hline $\begin{array}{l}\text { CORPO DE PROVA } \\
\text { (No) }\end{array}$ & FACE & $\begin{array}{l}\text { RETRAÇÃO POR SECAGEM } \\
\text { INDIVIDUAL (\%) }\end{array}$ & $\begin{array}{l}\text { RETRAÇÃO POR SECAGEM } \\
\text { MÉDIA (\%) }\end{array}$ & & \\
\cline { 3 - 6 } & & APÓS 5 DIAS DE SECAGEM & APÓS 7 DIAS DE SECAGEM & $\begin{array}{l}\text { APÓS 9 DIAS DE } \\
\text { SECAGEM }\end{array}$ & - \\
\hline 1 & $\mathrm{~A}$ & $-0,010$ & $-0,010$ & $-0,010$ & 0,01 \\
\cline { 2 - 6 } & $\mathrm{B}$ & $-0,008$ & $-0,008$ & $-0,008$ & $-0,009$ \\
\hline \multirow{2}{*}{3} & $\mathrm{~A}$ & $-0,009$ & $-0,009$ & $-0,014$ \\
\cline { 2 - 7 } & $\mathrm{B}$ & $-0,014$ & $-0,014$ & $-0,008$ \\
\hline
\end{tabular}

\section{CONCLUSÕES}

A análise dos resultados, permite concluir pela viabilidade da incorporação da concha de marisco na produção de blocos vazados de concreto simples para alvenaria. A viabilidade em questão, se insere, inclusive, no contexto da variação da formulação do traço do concreto, em que a brita foi substituída pelas 
conchas de marisco, em diferentes percentuais; Os blocos de concreto, portanto, produzidos com todos os percentuais de massa de conchas de marisco em substituição à equivalentes massas de brita $(0 \%, 10 \%, 15 \%$, $50 \%, 75 \%$ e $100 \%)$ podem ser usados na alvenaria com função estrutural, enquadrando-se, na classe B da NBR 6136:2016.

Outro fator que recomenda o uso dos blocos produzidos com qualquer percentual em massa de conchas de marisco em substituição à brita no traço de concreto, corresponde à retração linear, cujos valores encontrados, individuais e médio $(0,01 \%)$, encontram-se dentro da faixa de valor recomendada pela norma ABNT NBR 6136:2016 ( $\leq 0,065 \%)$.

A inexpressiva distância entre a unidade fabril empresarial de blocos vazados de concreto, que participou de modo colaborativo no presente estudo e os sítios de deposição dos resíduos de conchas de marisco, robustece a concepção de viabilidade do ponto vista da esfera econômica, por tornar viável o custo da logística de transporte.

A produção de blocos vazados de concreto simples para alvenaria, nas condições testadas no presente estudo, agregará vantagens econômicas e sociais, devendo, neste sentido, contribuir, como reflexo, para o despontar de novos postos de trabalho atrelados às surgentes atividades de beneficiamento das cochas de marisco para abastecimento da indústria produtora de blocos de concreto simples local, e para a redução dos impactos ambientais causados pelo descarte inadequado do resíduo resultante do beneficiamento da pesca artesanal de mariscos na comunidade Beira Mar II, município de Igarassu-PE.

\section{REFERÊNCIAS}

ABNT. Associação Brasileira De Normas Técnicas. NBR 12118: blocos vazados de concreto simples para alvenaria: métodos de ensaio. Rio de Janeiro, 2013a.

ABNT. Associação Brasileira De Normas Técnicas. NBR 6136: blocos vazados de concreto simples para alvenaria: requisitos. Rio de Janeiro, 2016.

BARBOSA, C. S.. Resistência e deformabilidade de blocos vazados de concreto e suas correlações com as propriedades mecânicas do material constituinte. Dissertação (Mestrado) - Universidade de São Paulo, São Paulo, 2004.

BACCI, D. L. C.; LANDIM, P. M. B.; ESTON, S. M.. Aspectos e impactos ambientais de pedreira em área urbana. Rev. Esc. Mina, Ouro Preto, v.59, n.1, 2006.

BESSLER, K. E.; RODRIGUES, L. C.. Os polimorfos de carbonato de cálcio: uma síntese fácil de aragonita. Química Nova, São Paulo, v.31, n.1, 2008.

BOICKO, A. L.; HOTZA, D.; SANT'ANNA, F. S. P.. Utilização das conchas da ostra Crassostrea gigas como carga para produtos de policloreto de vinila (pvc). In: SIMPÓsIO INTERNACIONAL DE QUALIDADE AMBIENTAL, 4. Anais. Porto Alegre: Abes, 2004.

BUTTLER, A. M.. Uso de agregados reciclados de concreto em blocos de alvenaria estrutural. Tese (Doutorado) Universidade de São Paulo, São Carlos, 2007.
CLEMENTINO, F. C.; BARROS, G. R.; DIAS E SANTOS, P. G.. Processo produtivo em uma indústria de artefatos de concreto. Monografia (Graduação) - Universidade Federal de Goiás, Goiânia, 2014.

DIEGUES, A. C.. O cultivo de camarão em cativeiro e a pesca artesanal. Revista Coletiva, n.1, 2010.

OLIVEIRA, B. M. C.; EL-DEIR, S. G.. Mariscagem: um desafio para o litoral norte de Pernambuco. Recife: Edufrpe, 2013.

OLIVEIRA, M. C. G.; CUNHA JÚNIOR, M. V.. As instituiçõesmemória do município de Igarassu/PE: lugares de informação. In: ENCONTRO NACIONAL DE PESQUISA EM CIÊNCIA DA INFORMAÇÃO, 17. Anais. Salvador: UFBA, 2016.

PETRIELLI, F. A. S.. Viabilidade técnica e econômica da utilização comercial da concha de ostra descartada na localidade do Ribeirão da Ilha, Florianópolis/SC. Dissertação (Mestrado) - Universidade Federal de Santa Catarina, Florianópolis, 2008.

SALVADOR FILHO, J. A. A.. Blocos de concreto para alvenaria em construções industrializadas. Tese (Doutorado) Universidade de São Paulo, São Carlos, 2007.

SANT'ANNA, F. S. P.. Projeto Valorização dos resíduos da Maricultura: Soluções tecnológicas para aproveitamento de 
conchas de ostras. Florianópolis: Universidade Federal de Santa Catarina, 2007.

SENISSE, J. A. L.. Influência do consumo de água, do teor de adição de microfibras de propileno, e do tipo de cimento no fenômeno da retração por secagem em concretos empregados em pisos. Tese (Mestrado) - Universidade Federal do Rio Grande do Sul, Porto Alegre, 2010.

SILVA-CAVALCANTI, J. S.. Biologia e exploração da Anomalocardia brasiliana por populações de ribeirinhos no estuário do Rio Goiana (PE-PB) nordeste do Brasil. Tese (Doutorado em Oceanografia) - Universidade Federal de Pernambuco, Recife, 2011.
SILVA, D.; DEBACHER, N. A.. Caracterização físico-química e microestrutural de conchas de moluscos bivalves provenientes de cultivos da região litorânea da Ilha de Santa Catarina. Química Nova, v.33, n.5, p.1053-1058, 2010.

TACHIZAWA, T.. Gestão Ambiental e Responsabilidade Social Corporativa. 5 ed. São Paulo: Atlas, 2007.

YOON, G.; KIM, B.; KIM, B.; HAN, S.. Chemical-mechanical caracteristical of crushed oyster-shell. Waste Management, v.23, n.9, p.825-834, 2003.

A CBPC - Companhia Brasileira de Produção Científica (CNPJ: 11.221.422/0001-03) detém os direitos materiais desta publicação. Os direitos referem-se à publicação do trabalho em qualquer parte do mundo, incluindo os direitos às renovações, expansões e disseminações da contribuição, bem como outros direitos subsidiários. Todos os trabalhos publicados eletronicamente poderão posteriormente ser publicados em coletâneas impressas sob coordenação da Sustenere Publishing, da Companhia Brasileira de Produção Científica e seus parceiros autorizados. Os (as) autores (as) preservam os direitos autorais, mas não têm permissão para a publicação da contribuição em outro meio, impresso ou digital, em português ou em tradução. 